Research, part of a Special Feature on Beyond Carbon: Enabling Justice and Equity in REDD+ Across Levels of Governance

\title{
From Carbon Projects to Better Land-Use Planning: Three Latin American Initiatives
}

\author{
Laura M. Rival $^{1}$
}

\begin{abstract}
I start with a discussion of the limits of the United Nations' Reducing Emissions from Deforestation and Forest Degradation and cobenefits (REDD+) program and the need to embed forest carbon within integrated ecosystem services on a landscape scale. By comparing a REDD+ project with two non-REDD+ projects, I show that there are diverse ways of applying the Earth system governance lens to address the continuing deterioration of goods and services provided by ecological systems. I then compare the valuation of ecosystem services and the governance of their provision in the three projects under review: Bolsa Floresta in the state of Amazonas, Brazil; Araçuaí Sustentável in the state of Minas Gerais, Brazil; and the Yasuní-Ishpingo Tambococha Tiputini Initiative in Ecuador. I show how each project has given birth to innovative mixed policies based on citizen mobilization. These dynamic hybrid policies are uniquely fitted to the particular ecological, historical, sociocultural, and political contexts in which they took root, contexts they help to transform. I conclude that result-based payment systems such as those envisaged for REDD+ have the potential to increase the production of additional carbon absorption capacity. However, they are not always appropriate or cost effective, nor do they substitute for command-and-control instruments, or for popular mobilization.
\end{abstract}

Key Words: Araçuaí Sustentável; Bolsa Floresta; Earth governance; landscapes under ecosystem-based management; payments for ecosystem services; REDD+ schemes; Yasuni-Ishpingo Tambococha Tiputini Initiative

\section{INTRODUCTION}

As a number of authors have argued, REDD+, which started as a climate-change mitigation strategy aimed at avoiding deforestation, gains in being understood through the lens of an Earth system governance framework (Folke et al. 2009, 2011, Corbera and Schroeder 2011). As a dynamic policy process, REDD+ also needs to be understood historically (Angelsen et al. 2012). In anticipation of emerging global compliance markets for forest carbon credits, REDD+ was initially aimed at creating a system by which payments would be made directly from the international level to individual forest users (Parker et al. 2009). Between 2005 and 2012, it was then promoted by tropical forest nations as a win-win policy through which financial compensation would be obtained for voluntarily keeping forests intact. The real innovation of a reduced emissions from deforestation (RED) approach was thus to create a performance-based support mechanism to diversify and substantially increase funding for forest conservation wherever carbon capture and retention could reliably be measured. This objective, according to a recent Center for International Forestry Research (CIFOR) study (Angelsen et al. 2012), was compromised with the incorporation of forest degradation (the second $\mathrm{D}$ in REDD) and cobenefits (the + in REDD+), which made REDD+ look increasingly similar to a previous generation of policies known as integrated conservation and development projects (ICDPs). Moreover, the current conjuncture, characterized by high prices for commodities and natural resources as well as by heightened competition for forestlands, has considerably increased the opportunity cost of both forest protection and of
REDD+ (Seymour and Angelsen 2012). This brings the authors of the CIFOR study to conclude that REDD+ can no longer exclusively depend on cash flows and payments for ecosystem services (PES) instruments, but will require "a skillful combination of instruments, including traditional command and control, law enforcement approaches, fiscal incentives and smarter infrastructure development and land planning" (Seymour and Angelsen 2012:331; see also Rival and Muradian 2012). Moreover, as a policy geared toward the maintenance of an optimal forest cover in the landscape, REDD+ will increasingly have to be financed as well as implemented by tropical forest nations themselves. Although REDD+ has changed significantly since it was first flagged as an international policy in the build-up to a global climate agreement, it continues to evolve today in the face of increased conflict between agriculture expansion and forest conservation. Many actors, including organizations in the private sector, are now envisaging forest carbon as only one aspect of a low-carbon economy and are looking at financing integrated ecosystem services on a landscape scale (United Nations Environment Programme 2011, Angelsen et al. 2012, Zang and Sahm 2012).

To learn from existing REDD+ programs, therefore, we not only need comparative studies such as those undertaken by CIFOR with its Global Comparative Study of REDD+, but also studies that compare REDD+ and non-REDD+ projects, because these will generate new insights regarding the dynamism and increased diversity of REDD policies in a conjuncture favoring their encompassment within broader 
sustainable ecosystem management goals. Studies focusing on coordination among the different levels of governance and the actors involved are particularly needed (Corbera and Schroeder 2011), especially if the focus is on context and implementation, rather than on design and modeling. Here I examine an iconic REDD+ project, Bolsa Floresta (hereafter BF). Its full name is the Forest Conservation Allowance Programme. I also examine the Yasuní-Ishpingo Tambococha Tiputini Initiative (Y-ITT), designed as an alternative to REDD+, and Araçuaí Sustentável (AS, Sustainable Araçuaí), a grassroots resilience movement and agroecological project linked only very indirectly to REDD+.

Whereas BF is a forest carbon project involving both payments for ecosystem services and integrated development and conservation projects, Y-ITT constitutes a unique government-led PES scheme aimed at avoiding carbon dioxide $\left(\mathrm{CO}_{2}\right)$ emissions by keeping oil in the ground, and AS represents a citizen-led resilience movement providing viable economic alternatives to out-migration in a nonforested area prone to desertification. Two of the projects, BF in the state of Amazonas and AS in the state of Minas Gerais, are located in an economically powerful leading forest nation, Brazil. The third, Y-ITT, is in Ecuador, a small country economically dependent on oil extracted from the Amazon region. Ultimately, the three projects involve innovative coordination pathways that move development decisions from business as usual to sustainable ecosystem management (Bovarnick et al. 2010) to do the following: (1) protect the carbon function of forests while bettering the lives of poor families who migrated to the Brazilian Amazon and who now live as illegal settlers within the boundaries of state protected areas (BF); (2) contain the oil and agriculture frontier in a region of high biological and cultural diversity, while providing alternative livelihoods to poor migrants who have settled in the Ecuadorian Amazon (Y-ITT); and (3) help poor small-scale farmers and seasonal migrant workers, who have not lost their land, but who struggle to sustain their families to restore soil fertility, increase and diversify production, and create local markets for their produce (AS).

My research on BF, Y-ITT, and AS is ongoing. The preliminary analysis presented here is based on data collected between 2006 and 2011, according to anthropological methods, in particular the extended case-study method (Burawoy 2009), a framework that stresses the constitutive role of conflict, the construction of moral discourses, and the inherent tensions between agency and structure within social networks. As ongoing projects, BF, Y-ITT, and AS have evolved substantially since their inception and continue to change. My analysis is therefore partial and is grounded in the questions and perspectives I have brought to empirical data collection (Rival 2012). I researched Y-ITT between 2005 and 2008 through ethnographic methods detailed in Rival 2010. In addition, I refer here to the work of Barnard (2011) and
Ruprecht (2011), as well as to Ecuador's February 21, 2011 Submission to the Fourteenth Session of the Ad Hoc Working Group on Long-Term Cooperative Action under the United Nations Framework Convention on Climate Change (Government of Ecuador 2011), and to conversations with government officials at Rio+20. I conducted research on BF during 2009 through interviews and participant observation in various meetings and workshops, both in Brazil and in the United Kingdom, as well as on a one-week visit to a community of the Rio Negro that had recently been integrated in the program. I also used various publications by Virgilio Viana (2008, 2009, 2010), Director of Fundaçaõ Amazonas Sustentável (FAS, Sustainable Amazonas Foundation); discussions with FAS employees and community representatives at Rio+20; and information publicly available on the FAS website (http://fas-amazonas.org/?lang=en). I carried out research on AS in May 2007 and May through June 2011 through participant observation and in-depth interviews with the following: Tiaõ Rocha, Director of Centro Popular de Cultura y Desenvolvimiento (CPCD, Centre for Popular Culture and Development); Flavia Mota, CPCD's project manager; various local educators and "caring mothers"; and two youths. I addition, I make use of information and testimonies found in various CPCD publications and on the organization's website (http://www.cpcd.org.br).

I briefly summarize the characteristics of each of the three initiatives. I compare them in terms of various sustainability issues, showing how they have facilitated the incorporation of economic and noneconomic values of ecosystem services into decision making and assessing their capacity to articulate development principles based on ecosystem stewardship and the promotion of resilience in the face of climate change (Chapin et al. 2009). I conclude with a few remarks on the future of the result-based payment systems that were initially envisaged for REDD+.

\section{THE THREE CASE STUDIES}

\section{Bolsa Floresta: Payments to avoid deforestation}

The BF program officially started in 2007 with the Juma Sustainable Development Reserve Project for Reducing Greenhouse Gas Emissions from Deforestation in the state of Amazonas, the first project to be nominally recognized as a RED project in Brazil. Initial funding came from the government of the state of Amazonas, Bradesco Bank, and the Coca-Cola Company. BF now includes 6800 families, spread over one million hectares within 15 legally protected areas, or state conservation units. A number of state laws were passed in 2007 and 2008 to create the legal framework for BF. The subnational PES legislation includes the creation of 30 statelevel conservation units as well as the FAS, the foundation in charge of implementing BF, and a new government unit that coordinates and executes the state's climate-change policy. There are also laws authorizing the two initial donations (each 
of $\mathrm{R} \$ 20$ million) from the state of Amazonas and from Bradesco, and laws specifying how the benefits from avoided deforestation will be shared. The legislation allows BF to receive funding from a wide range of sources, both through the Clean Development Mechanism (CDM) of the Kyoto Protocol and through the Amazon Fund, which funds only capacity-building activities. By law, all the revenues obtained must be reinvested in the management of the conservation units to promote forest conservation and to improve the quality of life of the inhabitants. BF is expected to generate around 171 million tons of $\mathrm{CO}_{2}$ credits over the duration of the funded project. The methodology to quantify carbon emission reduction through avoided deforestation was developed by the Instituto de Conservação e Desenvolvimento Sustentável do Amazonas (IDESAM, Institute for the Conservation and Sustainable Development of the State of Amazonas), a research nongovernmental organization founded in 2004.

Incentives to avoid deforestation include a combination of conditional direct payments to families (a monthly Family Forest Allowance); grants to community associations (Forest Allowance for Associations); social development programs (Social Forest Allowance); and the promotion of incomegenerating activities (Income Forest Allowance). There is also funding for monitoring, auditing, and administration. The monthly Family Forest Allowance (R \$50, or US\$28), which is modeled on the highly popular Bolsa Familia, is paid to registered married women with children who live in one of the conservation units covered by the program. The Forest Allowance for Associations, intended to strengthen community organization and social control mechanisms, amounts to $10 \%$ of the total value of the family allowances, and funds office support (Internet, solar panels, computers), transportation (speed boats), and logistics (fuel and food supplies). The Income Forest Allowance is designed to promote income-generating activities, and the Social Forest Allowance is invested in health, education, communication, and transport. Some aspects of BF's approach are modeled on Proambiente, the first formal PES scheme established in Brazil, which has paid small farmers to minimize deforestation and the use of fire, and to experiment with agroforestry. Initiated by grassroots organizations, Proambiente was transferred to the federal government in 2004; it currently suffers from a lack of sustained funding. With $90 \%$ of its financial resources coming from the private sector, FAS is hopeful that Brazilian private social investment initiatives will continue to keep BF afloat, even in the absence of global carbon markets.

\section{The Yasuní-Ishpingo Tambococha Tiputini Initiative: payments to avoid pollution from oil}

The Yasuní Initiative was officially endorsed by the Ecuadorian government in 2007, when President Correa pledged to leave 846 million barrels of heavy crude underground indefinitely in the oil fields lying beneath the
Yasuní National Park (YNP), which was designated a Man and the Biosphere Reserve for Humanity by the United Nations Educational, Scientific and Cultural Organization (UNESCO) in 1989. The park is one of the most biodiverse in the world and is home to indigenous groups living in voluntary isolation. Ecuador has asked for a compensation of US $\$ 3.6$ billion over 13 years to be deposited into a trust fund to offset half of the country's loss in revenue from oil. The Trust Fund, administered by the United Nations Development Programme (UNDP), and the interest it would generate, would then be used to finance a range of activities in line with the strategic National Development Plan to change the course of Ecuador's development path in the face of climate change. The capital in the Trust Fund will be invested in renewable energy projects, and the interest will be used to execute five different activities in line with the National Development Plan: (a) protect $38 \%$ of the national territory through deforestation prevention in 43 protected areas (4.8 million hectares) and through ecosystem management in additional areas $(5$ million hectares); (b) reforest, afforest, and promote the natural regeneration of 1 million hectares of forest owned by small landholders and indigenous communities; (c) increase national energy efficiency and savings; (d) promote social development in Y-ITT's buffer zone; and (e) finance scientific research and technology. If a future government ever decided to exploit the oil, the money invested plus interest would be returned to the contributors, with no more financial risk than is normally incurred with external debt repayments.

The total amount to be raised and administered by the Trust Fund is equivalent to 407 million tons of avoided $\mathrm{CO}_{2}$ emissions, valued according to the price of the European Union Allowances (EUAs), US\$19.81 per ton of $\mathrm{CO}_{2}$ at the signing date of Ecuador-UNDP's international agreement. Official negotiators stress that the amount of direct $\mathrm{CO}_{2}$ emissions that would be prevented with Y-ITT surpasses the annual emissions of France, 373 million tons, or Brazil, 332 million tons, and has a total economic value of US\$8.067 billion. As a funding mechanism, Y-ITT is designed to address North-South common but differentiated responsibilities. However, like BF, it only makes sense in the context of emerging international carbon markets, thus illustrating the extent to which the forest carbon idiom has facilitated the translation of the market value of crude oil into that of avoided carbon dioxide emissions.

Substantial international funding has not yet materialized, and the implementation of Y-ITT has not gone very much beyond the moratorium on oil extraction. Y-ITT has nevertheless already fostered a number of institutional changes within Ecuador's government structure. Many insights can be gained from analyzing the disagreements surrounding the policy process, the attempts to solve a number of technicalities, and the discussions that have accompanied the promises of international funding (Rival 2011). Furthermore, as found in 
a recent survey, 77\% of the Ecuadorian population is in favor of leaving the oil in ITT underground and supports the Yasuní Initiative (Barnard 2011). Finally, Y-ITT, which is supported by a broad coalition of state and nonstate actors in two of the oil-producing provinces and is being reappropriated by civil society in opposition to the further expansion of the oil frontier, has become a rallying banner against what the current administration refers to as 'resource nationalism.'

\section{Araçuaí Sustentável: markets that reconnect urban and rural areas}

Araçuaí Sustentável's objective is to reverse environmental degradation and boost the role of agriculture in the local economy, so that the poorest segment of the population can live comfortable and independent lives without having to migrate. The program is based on a philosophy of human life and ethical principles rooted in Paulo Freire's pedagogy of the oppressed. Araçuaí is located in the valley of the Jequitinhonha River. The municipality counts around 38,000 inhabitants; $57.3 \%$ live in the town and $42.7 \%$ in the surrounding rural areas. Like Bahia further north, the Jequitinhonha Valley is a poor, semiarid region from which people have had to migrate to survive. The river system has been drying in recent years, as a result of the building of dams for the expansion of eucalyptus plantations, some of which registered in PES schemes under the Clean Development Mechanism, and because of more severe droughts. Although mass migration to São Paulo or other parts of the country has now stopped, around 8000 men still leave their homes for nine months every year to cut sugar cane in central Brazil. The wives of cane cutters are locally known as "widows of living husbands." Given the importance of sugarcane ethanol in Brazil's economy, Araçuaí offers an interesting example of some of the tensions underpinning sustainable development decisions.

Activists from the Centro Popular de Cultura e Desenvolvimento (CPCD, the People's Center for Culture and Development) arrived in Araçuaí in 2003, and mobilized the population against illiteracy and semi-illiteracy until 2006. According to government statistics, only 3.3\% of Araçuaí children with eight years of schooling could read, write, and count. The literacy campaign took place outside of school hours in the houses of mothers trained as community leaders, before expanding into programs that transformed streets, squares, and whole neighborhoods into spaces of "permanent education" rooted in local popular culture. The citizens' movement was so successful that the municipality asked CPCD educators to run the city's educational services for two years, which they did free of charge. Three youth programs and social enterprises run for and by teenagers were also created.

In 2006, the literacy campaign was combined with a nature conservation and agroecology program. This is how, after eight years of popular education in both the urban and rural parts of the municipality and an intensive process of interinstitutional work, CPCD activists have fostered a citizens' movement that has given birth to an impressive array of programs that together form Araçuaí Sustentável, a new model of sustainable development for the region. Today, the five-hectare demonstration farm, cultivated according to agroecological principles, produces 28 tons of food each month. Thousands of rural women have joined the program and have applied AS's principles of simplicity, beauty, practicality, and self-reliance in their homes. Through social learning and community mobilization, they have since transformed large parts of the valley into a water-retaining landscape. In 2011, the year in which AS was voted runnerup to the Globe Sustainable City Award, 56 women were able to sell food, remedies, and handicrafts at a newly created weekly market in Araçuaí. Since then, the CPCD has partnered with the local technical university (Instituto Federal Norte de Minas Gerais) to develop a degree in agroecology and a water conservation and reforestation program.

\section{DISCUSSION}

The dynamic evolution of reduced emissions from deforestation policy tools shows how policy thinking has moved in recent years from treating carbon as a new commodity linked to the forestry sector toward looking at land use in terms of multiple services offered by landscapes under ecosystem-based management. A comparison of BF, a REDD+ project, with Y-ITT and AS, two very different but equally innovative sustainable development programs, illustrates how a shift toward the stewardship of interdependent social-ecological systems may occur in practice. With $\mathrm{BF}$, the shift occurs primarily through largescale forest conservation, including the promotion of farming without fire and the prevention of the conversion of protected forest into extensive pastures, combined with interventions aimed at improving quality of life in poor proconservation communities. With Y-ITT, stewardship of social-ecological systems starts with making the worth of petroleum greater under the ground than above it; the goal then is to take the whole nation on a new development path based on biodiversity conservation and respect for cultural diversity. AS makes clear that promoting an ethic of restoration that conjugates the repair of the social fabric with "Earth repair" is key to the stewardship of interdependent social-ecological systems. The shift thus involves programs that break the vicious circle of land degradation, out-migration and rural poverty, and reconnect inhabitants of small towns with surrounding rural communities.

\section{Recognizing, valuing, and paying for ecosystem services} The Amazon ecosystem is threatened by deforestation and degradation arising from road building, logging, mining, ranching, farming, and oil extraction, and by anthropogenic climate change, particularly through a potential increase in 
drought risk (Betts et al. 2008). BF and Y-ITT both represent efforts to value standing forests in the face of national governments' plans to develop their Amazon regions, and in the face of higher commodity prices for agricultural products and natural resources. BF has helped Brazilian policy makers, entrepreneurs, and citizens to value forest ecosystem services by quantifying its carbon stocks and using them to generate REDD+ payments. By preventing the loss of ecosystem services through fire, cattle ranching, and other land-use changes of low economic productivity in the long run, BF has also contributed to the mitigation of climate change. Y-ITT has made the values of biological and cultural diversity visible in the Yasuní. It has also increased national and international awareness about the need to quantify prevented $\mathrm{CO}_{2}$ emissions and stop the further expansion of the oil frontier in areas of great ecological wealth that are both vulnerable ecosystems and potential refugia for drought-intolerant species. Both BF and Y-ITT highlight the fact that climate change not only represents a global threat, but also interacts locally with land use in a way that is destructive of the ecosystem services on which many local and regional livelihoods depend. With its focus on cultivated landscapes in a degraded ecosystem that is prone to desertification, AS has facilitated water conservation and the restoration of ecological functions and their supporting ecosystem services. AS thus demonstrates how the colonization of pristine forest areas by poor farmers fleeing degraded and drought-prone lands may be prevented through ecological restoration.

Bolsa Floresta, which points to the role of financial organizations such as Bradesco Bank in environmental governance on various scales, explicitly promotes good forest stewardship in conservation areas through conditional cash transfers to households enrolled in the PES scheme. Y-ITT, by contrast, is designed to compensate oil-revenue losses and fund government-planned conservation and research and development activities nationally, as well as to make some interventions aimed at improving local well-being. In the absence of large-scale international funding, Y-ITT-related activities are being implemented with government funding and development assistance. Both AS and BF promote alternative production strategies in order to make small-scale agricultural production sustainable and more productive. No PES scheme has been designed as part of AS. Here, the issue is not so much to ensure that economic production will not hinder the reproductive capacity of ecosystem services, but, rather, to enhance the livelihoods of poor rural dwellers and create new local market activities as a means to restore ecosystem services. Taken together, the three initiatives thus illustrate the diversity of existing incentives for the conservation of ecosystems and the forms taken by some of the instruments designed for managing their provision (Muradian and Rival 2012).

\section{Social and political mobilization for resilient land-use planning}

The interplay among ecosystems, scales, and institutions in BF, Y-ITT, and AS illustrates the fact that ecosystem service governance defies conventional dichotomies between state and market, public and private, or regulation and incentive (Rival and Muradian 2012). Further research will establish whether the new scientific understanding of the complex and dynamic interrelations between society and nature, including its governance implications (Folke et al. 2011), have guided the design of BF, Y-ITT, and AS, or whether the hybrid governance institutions that have emerged in each case result from other factors. In any case, the three initiatives illustrate the importance of collective action in coordinating needed reforms across policies and sectors, and the central regulation and enforcement role that the state plays at multiple levels. BF would have never happened without the initiative of private companies, or without the mobilization of networked grassroots organizations, which played a central role in making this initiative possible (Rival 2012). Y-ITT, which was formulated by civil society organizations at least 10 years before becoming an official governmental initiative (Rival 2010), is today being reappropriated by social movements and broad coalitions, and German companies are signing research and development contracts with the Ecuadorian government to develop renewable energy on a national scale (Ruprecht 2011). AS, which has received generous funding from Petrobras, clearly demonstrates the key importance of ongoing community action and community-based volunteer networks in improving the provision of public goods, including ecosystem services. BF perfectly illustrates the different roles played by various levels of state bureaucracy, with the subnational government pushing against the federal government for legal reform, and Y-ITT demonstrates how novel regulatory mechanisms may foster transformative planning, which, in this particular context, corresponds to the central government's wider attempt to control the size and the role of oil revenues in the national economy. AS shows that close collaboration can occur between governmental institutions and mobilized citizens.

\section{CONCLUSION}

As Joshua Farley (2012:48) argues, the concept of ecosystem services is extremely helpful to guide decisions about allocating the resources provided by nature, "whether or not the end receiving highest priority is monetary value, quality of life, or the preservation of nature for its intrinsic values." Much can be learned from BF, Y-ITT, and AS for the design of future REDD+ policies that would lead to better land-use planning, considering that whole landscapes, rather than just forests, need to be managed and made more resilient in the face of changing climatic conditions. For each initiative, the language of ecosystem services has allowed shifts in policy away from treating the environment as an externality, and 
away from governing natural resources one by one. It has also made the costs and benefits of either development or conservation more explicit, thus allowing for a more transparent relationship between ecology and economics. In particular, it has clarified the fact that most ecosystem services are either common pool resources or public goods (Muradian and Rival 2012). Given that not all payments are market transactions, there is a qualitative difference between attributing a partially monetized value to ecosystem services and translating this value into an exchange value. Consequently, result-based payment systems such as those envisaged for REDD+ are not always appropriate or cost effective (Farley 2012, Muradian et al. 2013). The strong ethical discourse that accompanies AS and the intense discussions aroused by BF and Y-ITT amply show that the incorporation of the values of ecosystem services into decision making for the stewardship of social-ecological systems requires multicriteria valuation tools, as well as the recognition that normative value judgments are an intrinsic part of decision making (Flyvbjerg et al. 2012).

Responses to this article can be read online at:

http://www.ecologyandsociety.org/issues/responses. php/5563

\section{Acknowledgments:}

I wish to thank the anonymous peer reviewers and the Ecology and Society editors for their useful comments and valuable feedback on this article. This paper is partly based on research funded by ESPA (Ecosystem Services for Poverty Alleviation), whose financial support is gratefully acknowledged here.

\section{LITERATURE CITED}

Angelsen, A., M. Brockhaus, W. D. Sunderlin, and L. V. Verchot, editors. 2012. Analysing REDD+. Challenges and choices. CIFOR, Bogor, Indonesia. [online] URL: http:// www.cifor.org/online-library/browse/view-publication/ publication/3805.html

Barnard, A. 2011. We are the lungs of the world: popular environmentalism and the local politics of climate change in the Ecuadorian Amazon. Thesis in Development Studies. University of Oxford, Oxford, UK. Mimeo.

Betts, R., Y. Malhi, and J. T. Roberts. 2008. The future of the Amazon: new perspectives from climate, ecosystem and social sciences. Philosophical Transactions of the Royal Society $B$ 363(1498):1729-1735. http://dx.doi.org/10.1098/rstb.2008.0011

Bovarnick, A., F. Alpizar, and C. Schnell, editors. 2010. The importance of biodiversity and ecosystems in economic growth and equity in Latin America and the Caribbean: an economic valuation of ecosystem. United Nations Development Program, New York, New York, USA.

Burawoy, M. 2009. The extended case method: four countries, four decades, four great transformations, and one theoretical tradition. University of California Press, Berkeley, California, USA.

Chapin, F. S., G. P. Kofinas, and C. Folke, editors. 2009. Principles of ecosystem stewardship: resilience-based natural resource management in a changing world. Springer, London, UK.

Corbera, E., and H. Schroeder. 2011. Governing and implementing REDD+. Environmental Science and Policy 14:89-99. http://dx.doi.org/10.1016/j.envsci.2010.11.002

Farley, J. 2012. Ecosystem services: the economics debate. Ecosystem Services 1(1):40-49. http://dx.doi.org/10.1016/j. ecoser.2012.07.002

Flyvbjerg, B., T. Landman, and F. Schram, editors. 2012. Real social science: applied phronesis. Cambridge University Press, Cambridge, UK. http://dx.doi.org/10.1017/ CBO9780511719912

Folke, C., F. S. Chapin III, and P. Olsson. 2009. Transformations in ecosystem stewardship. Pages 103-125 in F. S. Chapin, G. P. Kofinas, and C. Folke, editors. Principles of ecosystem stewardship: resilience-based natural resource management in a changing world. Springer, London, UK. http://dx.doi.org/10.1007/978-0-387-73033-2 5

Folke, C., Å. Jansson, J. Rockström, P. Olsson, S. R. Carpenter, F. S. Chapin III, A.-S. Crépin, G. Daily, K. Danell, J. Ebbesson, T. Elmqvist, V. Galaz, F. Moberg, M. Nilsson, H. Österblom, E. Ostrom, Å. Persson, G. Peterson, S. Polasky, W. Steffen, B. Walker, and F. Westley. 2011. Reconnecting to the biosphere. Ambio 40:719-738. http://dx.doi. org/10.1007/s13280-011-0184-y

Government of Ecuador. 2011. Submission to the Fourteenth Session of the Ad Hoc Working Group on long-term cooperative action under the United Nations framework convention on climate change. United Nations Framework Convention on Climate Change, Geneva, Switzerland. [online] URL: http://unfccc.int/resource/docs/2011/awglca14/ eng/misc02a02.pdf

Muradian, R., and L. Rival. 2012. Between markets and hierarchies: the challenge of governing ecosystem services. Ecosystem Services 1(1):93-100. http://dx.doi.org/10.1016/j. ecoser.2012.07.009

Muradian, R., M. Arsel, L. Pellegrini, F. Adaman, B. Aguilar, B. Agarwal, E. Corbera, D. E. de Blas, J. Farley, G. Froger, E. Garcia-Frapolli, E. Gómez-Baggethun, J. Gowdy, N. Kosoy, J. F. Le Coq, P. Leroy, P. May, P. Méral, P. Mibielli, 
R. Norgaard, B. Ozkaynak, U. Pascual, W. Pengue, M. Perez, D. Pesche, R. Pirard, J. Ramos-Martin, L. Rival, F. Saenz, G. Van Hecken, A. Vatn, B. Vira, and K. Urama (2013). Payments for ecosystem services and the fatal attraction of win-win solutions. Conservation Letters. http://dx.doi.org/10.1111/ j.1755-263X.2012.00309.X

Parker, C., A. Mitchell, M. Trivedi, N. Mardas, and K. Sosis. 2009. The Little REDD+ Book: an updated guide to governmental and non-governmental proposals for reducing emissions from deforestation and degradation. Global Canopy Foundation, Oxford, UK. [online] URL: http://www. theredddesk.org/sites/default/files/lrb en.pdf

Rival, L. 2010. Ecuador's Yasuní-ITT Initiative: the old and new values of petroleum. Ecological Economics 70:358-365. http://dx.doi.org/10.1016/j.ecolecon.2010.09.007

Rival, L. 2011. Planning development futures in the Ecuadorian Amazon: the expanding oil frontier and the Yasuní-ITT Initiative. Pages 155-173 in A. Bebbington, editor. Social conflict, economic development and extractive industry: evidence from South America. Routledge, New York, New York, USA.

Rival, L. 2012. Sustainable development through policy integration in Latin America: a comparative approach. Occasional paper 7. Social dimensions of green economy and sustainable development. United Nations Research Institute for Social Development (UNRISD), Geneva, Switzerland. [online] URL: http://www.unrisd.org/80256B3C005BCCF9/ search/DA1744ED6C1FFD03C12579F3002A5769?OpenDocument

Rival, L., and R. Muradian 2012. Introduction. Pages 1-20 in R. Muradian and L. Rival, editors. Governing the provision of ecosystem services. Springer, Dordrecht, Netherlands, and New York, New York, USA.

Ruprecht, N. 2011. Y-ITT: a policy for normative change hindered by political norms? Thesis in Global Governance and Diplomacy. University of Oxford, Oxford, UK. Mimeo.

Seymour, F., and A. Angelsen. 2012. Summary and conclusions: REDD+ without regrets. Pages 317-334 in A. Angelsen, M. Brockhaus, W. D. Sunderlin, and L. V. Verchot, editors. Analysing REDD+: challenges and choices. CIFOR, Bogor, Indonesia. [online] URL: http://www.cifor.org/ online-library/browse/view-publication/publication/3805.html

United Nations Environment Programme (UNEP). 2011. Towards a green economy: pathways to sustainable development and poverty eradication. UNEP, Nairobi, Kenya. [online] URL: www.unep.org/greeneconomy/NewGER/ tabid/79054/language/en-US/Default.aspx

Viana, V. M. 2008. Bolsa Floresta: um instrumento inovado para a promoção da saúde em comunidades tradicionais na Amazônia [Bolsa Floresta: an innovative mechanism to promote health in traditional communities in the Amazon]. Estudos Avançados 22(64):143-153. http://dx.doi.org/10.1590/ $\underline{\text { S0103-40142008000300009 }}$

Viana, V. M. 2009. Solving the "REDD" puzzle. Amazonas Sustainable Foundation. Manaus, Brazil. [translated by Matthew D. Quinlan and Marina T. Campos]. [online] URL: http://ebookbrowse.com/desatando-o-n\%C3\%B3-traduzidoing1\%C3\%8As-pdf-d420594307

Viana, V. M. 2010. Sustainable development in practice: lessons learned from Amazonas. Environmental Governance No. 3. International Institute for Environment and Development, London, UK. [online] URL: http://pubs.iied. org/pdfs/17508IIED.pdf

Zang, A., and M. Sahm. 2012. REDD as a catalyst to drive sustainable land use. Pages 78-79 in G. Nichols-Roth, editor. Climate change: the new economy. The New Economy, Ltd., United Nations Environment Programme, London, UK. [online] URL: http://view.digipage.net/?id=rio20climatechange 